\title{
Origin of Right Coronary Artery (RCA): A Multidetector Computed Tomography (MDCT) Coronary Angiographic (CA) Study in North India
}

\author{
Sushma Tomar', P K Sharma², Punita Manik ${ }^{3}$, Manoj Kumar ${ }^{4}$ \\ ${ }^{1}$ Assistant Professor Department of Anatomy, King George's Medical University UP, Lucknow, ${ }^{2}$ Professor \& Head Department of Anatomy, Era Lucknow \\ Medical College, Lucknow, ${ }^{3}$ Professor, Department of Anatomy, King George's Medical University UP, Lucknow, ${ }^{4}$ Professor, Department of \\ Radiodiagnosis, King George's Medical University UP, Lucknow.
}

\section{Abstract}

Introduction: Several clinical and pathological scenarios like hemodynamic procedures, cardiac surgery in heart trauma and arrhythmias from coronary occlusive disease management have importance of variations in the origin of Right Coronary Artery (RCA). The RCA presents a wide spectrum of morphological expressions regarding its sites of origin, course, branches, length, size and termination. RCA usually arises from the Anterior Aortic Sinus (AAS) and traverses through the right atrio-ventricular (AV) groove. Subjects and Methods: In the present study, Computed Tomographic (CT) coronary angiograms of 50 routine subjects of different age groups who came to the Department of Radiodiagnosis, King George's Medical University UP, Lucknow in the year 2010- 2011 with known or suspected coronary artery disease, were analyzed. Coronary angiography (CA) was performed on a 64 slice Multidetector Computed Tomographic (MDCT) scanner, using retrospective electrocardiographic (ECG) gating. The incidence of different sites of origin of RCA was assessed. Results: In the present study, RCA originated from Anterior Aortic Sinus (AAS) in 47 (94\%) subjects. In 3 (6\%) subjects, RCA showed anomalous origin from Left Posterior Aortic Sinus (LPAS). These three subjects were males [3(9.38\%)]. In all the subjects, the course of RCA was normal except three males having origin of RCA from LPAS. In these three males, the proximal part of RCA coursed between Right Ventricular Outflow Tract (RVOT) and aorta. Conclusion: Most common site for origin of RCA was AAS. Anomalous origin of RCA was seen only from LPAS. Anomalous origin of RCA was seen only in male subjects. In all subjects having anomalous origin of RCA from LPAS, RCA coursed between pulmonary trunk and ascending aorta.

Keywords: Coronary Angiography, Multidetector Computed Tomography, North India, Origin, Right Coronary Artery

Corresponding Author: Dr. Sushma Tomar, Assistant Professor Department of Anatomy, King George's Medical University UP, Lucknow.

Received: February 2019

Accepted: March 2019

\section{Introduction}

The Right Coronary Artery (RCA) presents a wide spectrum of morphological expressions regarding its sites of origin, course, branches, length, size and termination. The knowledge of these variations is extremely important for their implications in surgical procedures and clinical events. RCA arises from the anterior ('right coronary') Aortic Sinus (AAS). The artery reaches the crux of the heart and ends a little to the left of it, often by anastomosing with the circumflex branch of left coronary artery. ${ }^{[1]}$ Anomalous origin of RCA is a rare congenital anomaly that was first described in 1948 by White NK and Edwards JE. ${ }^{[2]}$ In an angiographic study, Yamanaka $\mathrm{O}$ and Hobbs RE described that anomalous origin of RCA from left sinus of Valsalva, is a congenital abnormality with $0.107 \%$ incidence. ${ }^{[3]}$ Topaz O, et al found that the RCA is the most common anomalous vessel. ${ }^{[4]}$

Congenital coronary anomalies are associated with sudden death and exercise-related death. Taylor A J, et al observed that anomalous origin of RCA from left coronary sinus was the second most frequent anomaly and they reported that there is risk of sudden cardiac death with exercise in younger patients (less than or equal to 30 years old) with an isolated coronary artery anomaly. With age, the risk of sudden death decreases. Younger patients (less than or equal to 30 years old) were significantly more likely than older patients (greater than or equal to 30 years old) to die suddenly or during exercise despite their low frequency of significant atherosclerotic coronary artery disease. ${ }^{[5]}$ Anomalous aortic origin of a coronary artery (AAOCA) is the second most common cause of sudden cardiac death (SCD) in young athletes. It is postulated that occlusion or compression of the anomalous coronary artery during exercise leads to myocardial ischemia and subsequent lethal 
ventricular arrhythmia (ventricular tachycardia and fibrillation). According to available evidences the prevalence of anomalous right coronary artery (ARCA) is approximately six times more than anomalous left coronary $\operatorname{artery}(\mathrm{ALCA}) .{ }^{[6]}$

RCA may arise from different anomalous sites. Cansel M, et al reported origin of RCA from Left Anterior Descending (LAD) artery which is a very rare coronary anomaly. ${ }^{[7]}$ Zamani $\mathrm{J}$ and Mahmmody $\mathrm{Y}$ reported origin of RCA from LCA ${ }^{[8]}$ RCA arising from the main LCA accounts for only $0.65 \%$ of coronary artery anomalies. ${ }^{[9]}$ Kragel $\mathrm{AH}$ and Roberts WC studied the correlation between coronary dominance and anomalous origin of coronary artery and they found that the coronary dominance is useful to distinguish clinically significant anomalies from clinically insignificant anomalies. ${ }^{[0]}$ The incidence of coronary anomalies in patients undergoing coronary angiography varies from $0.64 \%$ to $1.3 \%$. Many of these anomalies are clinically benign; however, others are associated with serious morbidity. ${ }^{[11]}$

Knowledge of normal anatomy of RCA and its variations or anomalies is of paramount importance in heart surgeries. Inability to detect these anomalies may lead to complications. ${ }^{[12]}$ Several clinical and pathological scenarios like hemodynamic procedures, cardiac surgery in heart trauma and arrhythmias from coronary occlusive disease management have importance of variations in the origin of RCA.

The aim of this study was to assess the incidence of different sites of origin of RCA in subjects of North India and to find any anatomic variant.

\section{Subjects and Methods}

\section{Materials}

In this study, digital copies of CT coronary angiograms of 50 subjects of both sex and different age groups [32 males (14-75 years), 18 females (12-70 years); mean age $51.36 \pm 14.07$ years, age range $12-75$ years] were analyzed after taking due permission from Institutional Ethical Committee.

\section{Method}

This was an observational study. Coronary Angiography (CA) was done on patients came to the Department of Radiodiagnosis, King George's Medical University UP, Lucknow in the year 2010- 2011 with known or suspected coronary artery disease.

\section{Inclusion criteria}

Patients presenting with symptoms and signs of cardiovascular diseases e.g. Chest pain and Dyspnoea.

\section{Exclusion criteria}

(1) Lack of consent.

(2) Renal insufficiency (High urea / creatinine level).

(3) Allergy to contrast agent.

(4) Contraindication to radiation exposure (e.g. pregnancy).

(5) Uncontrolled Heart rate.

(6) Atrial fibrillation, frequent atrial or ventricular ectopics

\section{(>1/minute).}

(7) Unable to hold breath for 20 seconds.

CA was performed on 64 Slice Multidetector Computed Tomographic (MDCT) scanner (BRILLIANSTMCT, Version 2.45.22042, manufactured by Philips) which is installed in the department of Radiodiagnosis, King George's Medical University (KGMU), Lucknow, Uttar Pradesh (U.P.), India. Retrospective Electrocardiographically gated imaging was performed (Technical parameters are given in [Table 1]).

\begin{tabular}{|c|c|}
\hline $\begin{array}{l}\text { Table 1: Technical Parameters appl } \\
\text { Tomographic Coronary Angiographic } \\
\text { acquisition }\end{array}$ & $\begin{array}{l}\text { in Computed } \\
(C T C A) \text { images }\end{array}$ \\
\hline \multicolumn{2}{|c|}{$\begin{array}{c}\text { DEVICE - BRILLIANSTMCT, Version 2.45.22042, manufactured } \\
\text { by Philips }\end{array}$} \\
\hline Slices/collimation & $64 / 0.625 \mathrm{~mm}$ \\
\hline Effective temporal resolution (with $180^{\circ}$ algorithm) & $165 \mathrm{~ms}$ \\
\hline Tube current & $800 \mathrm{mAs}$ \\
\hline Pitch & 0.2 \\
\hline Tube voltage & $120 \mathrm{kV}$ \\
\hline Tube rotation time & $400 \mathrm{~ms}$ \\
\hline Section thickness & $0.9 \mathrm{~mm}$ \\
\hline Reconstruction Increment & $0.45 \mathrm{~mm}$ \\
\hline Field of view (FOV) & $220 \mathrm{~mm}$ \\
\hline ECG gating & Retrospective \\
\hline Isotropic voxel resolution & $0.4 \times 0.4 \times 0.4 \mathrm{~mm}$ \\
\hline Scanning time & $10-12$ seconds \\
\hline
\end{tabular}

\section{Pre-procedure precautions}

- The subjects were enquired, to rule out the presence of any drug allergy to avoid the occurrence of any untoward anaphylactic reaction during the procedure.

- Two days prior to the procedure the subjects were advised to avoid the intake of fatty food.

- They were advised to drink only water just prior to the procedure.

- Blood urea and creatinine levels were evaluated.

\section{Procedure}

The subjects were laid supine. Their heart rate was stabilized with an oral dose of 50-100 mg Metoprolol one hour before the scan. If heart rate was not stabilized with an oral dose, then intravenous (IV) Metoprolol was given. Electrocardiogram (ECG) and pulse rate were monitored half an hour prior to the procedure. The subjects were counseled to reduce their anxiety.

The subjects were connected to a cardiac monitor. For venous access, an upper extremity vein (antecubital vein) and a 20-gauge intravenous canula was used. $80-85 \mathrm{ml}$ of non- ionic contrast Iohexol (Omnipaque, GE, GE Healthcare Ireland, Cork) containing iodine concentration of 350 $\mathrm{mgI} / \mathrm{ml}$, injected with a flow rate of $5.5 \mathrm{ml} / \mathrm{sec}$, followed by a $20 \mathrm{ml}$ saline flush at a rate of $4 \mathrm{ml} / \mathrm{sec}$ with a pressure injector (PSI-325). The scan timing was determined with automated bolus tracking technique by placing the region of interest over mid ascending aorta and setting the trigger threshold to 180 Hounsfield (Hu). The subjects were asked to lie still on the "scanning bed" for a period of 5-10 minutes. The instruction was given to the subjects to maintain an inspiratory breath hold during which CT data and ECG tracings were taken. CTCA was performed 5 seconds after aortic peak density. Scanning coverage was from the level of carina to the bottom of the heart. Raw 
spiral CT data of coronary arteries were reconstructed in various phases of cardiac cycle on a work station (Brilliance 64 version 4.5) to obtain images with the highest quality (without motion artefact).Reconstruction performed at $75 \%$ of R-R interval was found to be optimal for image analysis in most of the subjects. In some, if heart rate could not be stabilized properly, then reconstructions were performed at $45 \%$ of R-R interval. The images generated were reconstructed and viewed utilizing a separate workstation which enabled generation of the coronary arteries in the standard and in various other anatomical planes as and when required and were interpreted with the help of a cardiac radiologist. Subjects with previous bypass surgery and also those with suboptimal study due to breath hold artefacts were excluded.

All images were reviewed first in axial projection and then with post processing tools such as Multiplanar Reconstruction (MPR), Curved Planar Reformation (CPR), thin-slab Maximum Intensity Projection (MIP), and Volume-Rendering Technique (VRT) with transparent background display. MIPs were obtained using various thicknesses (5-30 mm). Volume-rendered (VR) images were also obtained using various orientations.

CTCA images were observed for the origin of RCA. The statistical analysis was performed by using software SPSS (Statistical Package for Social Sciences) version 15.0. The values were represented in Number (\%) and Mean \pm Standard Deviation (SD).

\section{Result}

In the present study, RCA originated from Anterior Aortic Sinus (AAS) in $47(94 \%)$ subjects [29 $(90.63 \%)$ males and $18(100 \%)$ females] [Table 2, Figure 1a, b \& c]. $3(6 \%)$ subjects [3(9.38\%) males] showed anomalous origin of RCA from Left Posterior Aortic Sinus (LPAS) [Table 2, Figure $2 a, b \& c)$,$] . In all subjects, the course of RCA was normal$ except three male subjects who had anomalous origin of RCA from LPAS. In these three male subjects, the proximal part of RCA coursed between Right Ventricular Outflow Tract (RVOT) and aorta. [Figure 3a\&b]

\begin{tabular}{l}
\hline Table 2: Frequency of different sites of origin of RCA \\
\begin{tabular}{|l|l|l|l|}
\hline Site of Origin & Male $(\mathbf{N m}=\mathbf{3 2})$ & Female( Nf=18) & Total (Nt=50) \\
\hline AAS & $29(90.63 \%)$ & $18(100 \%)$ & $47(94 \%)$ \\
\hline LPAS & $3(9.38 \%)$ & $0(0 \%)$ & $3(6 \%)$ \\
\hline
\end{tabular}
\end{tabular}

Nm-Total number of males, Nf-Total number of females, Nt-Total number of study subjects
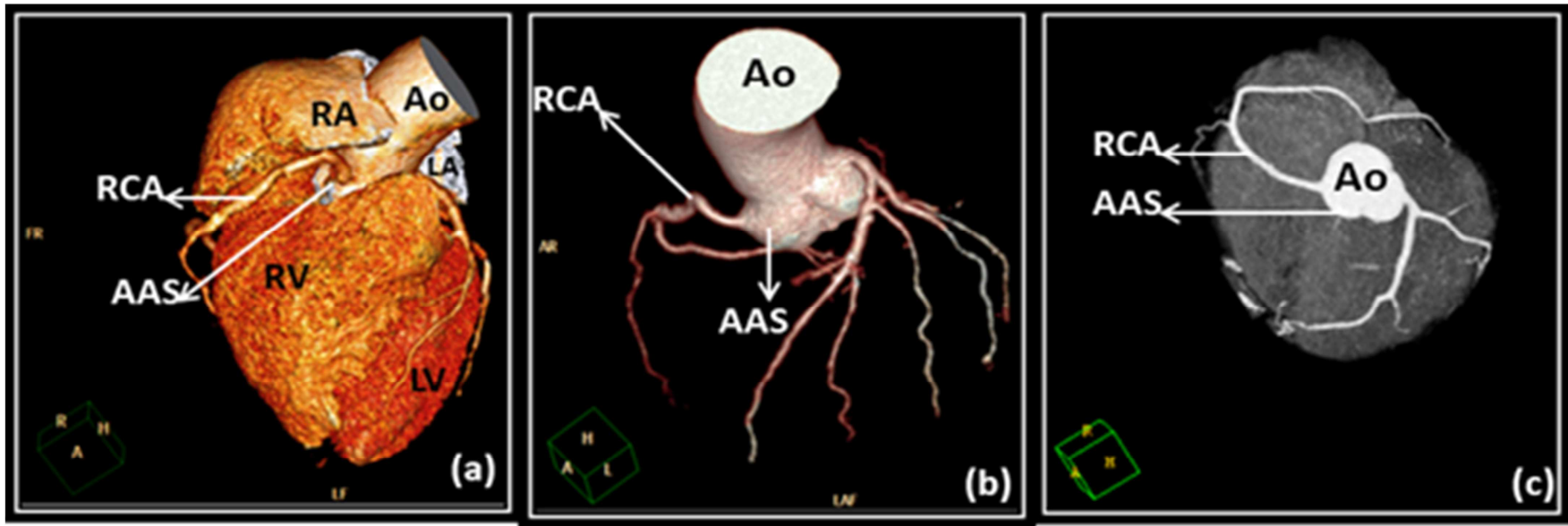

Figure 1: MDCT Images showing Normal Origin of RCA from AAS (a) 3D VR Image, (b) 3D VR Image (Contrast Vessel Tracking Tree), (c) MIP Image RA- Right Atrium, RV- Right Ventricle, LA- Left Atrium, LV- Left Ventricle, Ao- Aorta, AAS- Anterior Aortic Sinus, RCA- Right Coronary Artery
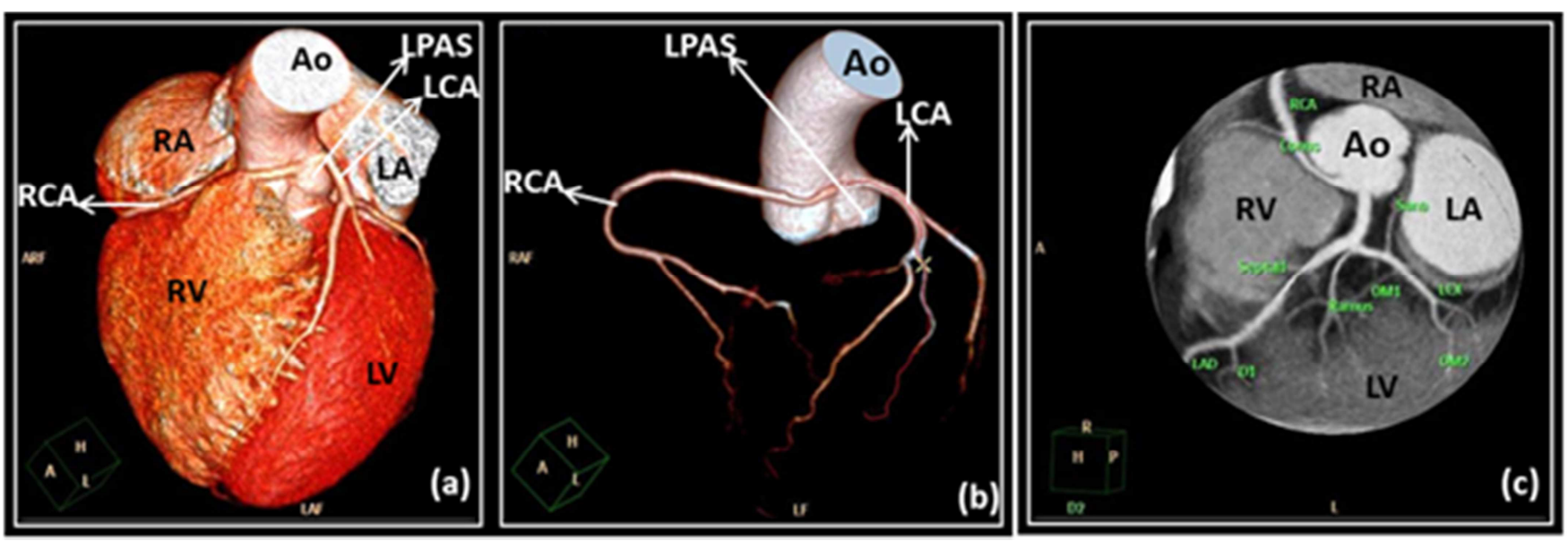

Figure 2: MDCT Images showing Anomalous Origin of RCA from LPAS (a) 3D VR Image, (b) 3D VR Image (Contrast Vessel Tracking Tree), (c) MIP Image RA- Right Atrium, RV- Right Ventricle, LA- Left Atrium, LV- Left Ventricle, Ao- Aorta, LPAS- Left Posterior Aortic Sinus, RCA- Right Coronary Artery, LCA- Left Coronary Artery 


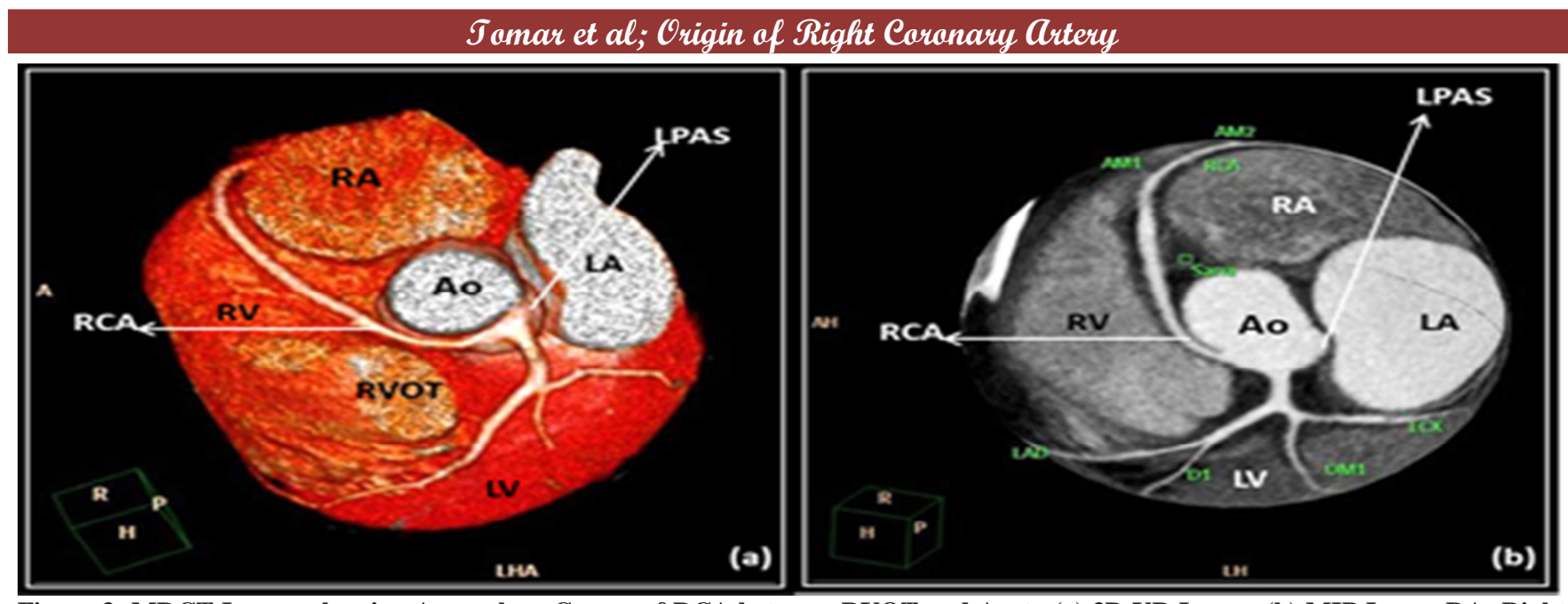

Figure 3: MDCT Images showing Anomalous Course of RCA between RVOT and Aorta (a) 3D VR Image, (b) MIP Image RA- Right Atrium, RV- Right Ventricle, LA- Left Atrium, LV- Left Ventricle, RVOT- Right Ventricular Outflow Tract (RVOT), Ao- Aorta, LPAS- Left Posterior Aortic Sinus, RCA- Right Coronary Artery

\section{Discussion}

The origin of coronary arteries shows great variability. ${ }^{[1]}$ Several studies have been done in the past regarding the origin of RCA [Table 3, 4, 5 \& 6]. The most common site of origin of RCA is AAS. In the present study, RCA arose from AAS in majority of cases (94\%). Our findings are similar to the reports of a cadaveric study done by Lufukuja G J $(94.7 \%)$ [Table 3]. ${ }^{[13]}$ In some cadaveric studies, RCA arose from AAS in $100 \%$ cases[Table 3]. ${ }^{[14-18]}$

Table 3: Incidence of Normal Origin of RCA from AAS
\begin{tabular}{|l|l|l|l|}
\hline Authors \& Year of Study & Type of Study & Population \& No. of Cases & Origin of RCA from AAS \\
\hline Kalpana R. 2003 & Cadaveric & South Indian, 100 & $100 \%$ \\
\hline Jim MH, et al. 2004 & Catheter Angiography & 1532 & $1519(99.2 \%)$ \\
\hline Fazliogullari Z, et al. 2010 & Cadaveric & Turkish, 50 & $100 \%$ \\
\hline Kulkarni JP. 2013 & Cadaveric & Western Indian, 60 & $100 \%$ \\
\hline Lufukuja G J. 2016 & Cadaveric & Tanzanian, 75 & $71(94.7 \%)$ \\
\hline Reddy MV, Pusala B. 2016 & Cadaveric & South Indian, 110 & $100 \%$ \\
\hline Bhele AV, et al. 2017 & Cadaveric & Western Indian, 50 & $100 \%$ \\
\hline Dhobale MR, et al. 2018 & Cadaveric & Western Indian, 150 & $148(98.67 \%)$ \\
\hline Present study. 2011 & 64-slice CT Angiography & North Indian, 50 & $47(94 \%)$ \\
\hline
\end{tabular}

Table 4: Incidence of Anomalous Origin of RCA from LPAS and RPAS among Autopsy and Cadaveric Studies

\begin{tabular}{|l|l|l|l|l|}
\hline Authors \& Year of Study & Type of Study & $\begin{array}{l}\text { Population \& } \\
\text { No. of Cases }\end{array}$ & \multicolumn{2}{|l|}{ Site of origin of RCA } \\
\cline { 3 - 5 } & & LPAS & RPAican, 18950 \\
\hline Alexander RW, Griffith GC. 1956 & Autopsy & Italian, 1200 & 7 & \\
\hline Frescura C, et al. 1998. & Autopsy & Tanzanian, 75 & $1(1.3 \%)$ & \\
\hline Lufukuja GJ. 2016 & Cadaveric & Western Indian, 150 & $2(1.33 \%)$ & \\
\hline Dhobale MR, et al. 2018 & Cadaveric & & \\
\hline
\end{tabular}

Table 5: Incidence of Anomalous Origin of RCA from LPAS and RPAS among Catheter Angiographic Studies

\begin{tabular}{|c|c|c|c|}
\hline \multirow[t]{2}{*}{ Authors \& Year of Study } & \multirow[t]{2}{*}{ Population \& No. of cases } & \multicolumn{2}{|c|}{ Site of origin of RCA } \\
\hline & & LPAS & RPAS \\
\hline Chaitman BR, et al. 1976 & Canadian, 3750 & 6 & \\
\hline Kimbiris D, et al. 1978 & American, 7000 & 12 & \\
\hline Wilkins CE, et al. 1988 & American, 10,672 & 30 & \\
\hline Yamanaka O, Hobbs RE. 1990 & American, 126595 & 136 & 4 \\
\hline Topaz O, et al. 1992 & 13010 & 35 & 14 \\
\hline Kaku B, et al. 1996 & Japanese, 17731 & 44 & \\
\hline Kardos A, et al. 1997 & Central European, 7694 & & 1 \\
\hline Garg N, et al. 2000 & North Indian, 4100 & 15 & 4 \\
\hline Angelini P et al, 2002 & American, 1950 & $18(0.92 \%)$ & $22(1.13 \%)$ \\
\hline Ayalp R, et al. 2002 & Turkish, 5253 & 2 & \\
\hline Harikrishnan S, et al. 2002 & 7400 & 7 & \\
\hline Jim MH, et al. 2004 & 1532 & $13(0.8 \%)$ & \\
\hline Rigatelli G, et al. 2004 & Italian, 5450 & 2 & \\
\hline Eid AH, et al. 2009 & Lebanese, 4650 & $9(0.19 \%)$ & \\
\hline Ouali S, et al. 2009 & Tunisian, 7330 & 3 & 1 \\
\hline Solanki P, et al. 2010 & American, 2120 & 8 & \\
\hline Aydar Y, et al. 2011 & Turkish, 7810 & 12 & 1 \\
\hline Sohrabi B, et al. 2012 & Irani, 6065 & $6(0.1 \%)$ & \\
\hline Tuo G, et al. 2013 & Italian, 7960 & 13 & \\
\hline Lingaraju S, et al. 2016 & North Indian (West Rajasthani), 8500 & 34 & 4 \\
\hline T"urko glu S, et al. 2018 & Turkish, 5165 & 16 & \\
\hline
\end{tabular}




\section{Tamar et al; Origin of Right Caranary Artery}

Several past studies reported the origin of RCA from anomalous sites such as LPAS, Right Posterior Aortic Sinus (RPAS), descending thoracic aorta, Pulmonary trunk, LCA, Left Circumflex (LCx) artery, LAD artery etc [Table 4, 5 \& $6]$. After analyzing the findings of these studies, we found that the most common site for anomalous origin of RCA is LPAS. Chaitman BR, et al observed that aberrant ostium of RCA in LPAS is invariably in front of the ostium of LCA. ${ }^{[19]}$ But orifice for the ectopic RCA may be present posterior to the left main ostium as found by Yamanaka $\mathrm{O}$ and Hobbs RE. ${ }^{[3]}$ There are three subtypes of this anomalous RCA based on the anatomic course. Retroaortic, if the anomalous artery traverses posterior to the ascending aorta; Interarterial, if it runs between the ascending aorta and pulmonary trunk and in third variant it courses anterior to the pulmonary trunk. ${ }^{[20]}$ In some studies, it is reported that the RCA coursed anterior to aorta in patients in whom it originated from LPAS.$^{[19,21-28]}$ In the present study also, anomalously originated right coronary arteries coursed anterior to aorta. RCA is at high risk when it arises from LPAS and coursed between pulmonary artery and aorta. ${ }^{[5]}$

Shu-shui W, et al named this kind of aberrant RCA with interarterial course as 'Coronary Artery Sandwich Anomaly. ${ }^{[29]}$ Ziegler FV, et al reported proximal intramural course of anomalous RCA originated from left sinus of Valsalva. ${ }^{[30]}$

\begin{tabular}{|c|c|c|c|c|}
\hline \multirow[t]{2}{*}{ Authors \& Year of Study } & \multirow[t]{2}{*}{ Type of Study } & \multirow{2}{*}{$\begin{array}{l}\text { Population \& } \\
\text { No. of Cases }\end{array}$} & \multicolumn{2}{|c|}{ Site of origin of RCA } \\
\hline & & & LPAS & RPAS \\
\hline Schmitt R, et al. 2005. & 4 and 16 row MDCT Angiography & German, 1758 & 11 & \\
\hline Hou KY, et al. 2007 & 64-slice CT Angiography & Chinese, 540 & $8(1.5 \%)$ & \\
\hline El-Sharkawy EM. 2007 & 64-slice CT Angiography & Egyptian, 1000 & 5 & \\
\hline ten Kate GJR, et al. 2008 & 64-sliceCT Angiography & Europian, 1000 & 5 & \\
\hline Srinivasan KG, et al. 2008 & 64-slice CT Angiography & South Indian, 1495 & 1 & \\
\hline Ziegler FV, et al. 2009 & CT Angiography & American, 748 & 8 & \\
\hline Yildirim D, Oruc F. 2009 & EBT Coronary Angiography & Turkish, 454 & 1 & \\
\hline Shabestari AA, et al. 2012 & 64-slice CT Angiography & Irani, 2697 & $12(0.44 \%)$ & $1(0.03 \%)$ \\
\hline Abdulghaffar W, et al. 2012 & 64-slice CT Angiography & Arabian, 840 & 4 & \\
\hline Kayan M, et al. 2012 & 128-slice CT Angiography & Turkish, 83 & 1 & 1 \\
\hline Opolski MP, et al. 2013 & CT Angiography & 8522 & 20 & \\
\hline Park JH, et al. 2013 & MDCT Coronary Angiography & Korean, 1582 & $7(0.44 \%)$ & \\
\hline Oliveira CA, et al. 2014 & MSCT Coronary Angiography & Portiguese, 663 & 4 & \\
\hline Krupinski M, et al. 2014 & CT Angiography & 7115 & 16 & \\
\hline Namgung J, Kim JA. 2014 & 64 or 320 slice MDCT Angiography & Korean, 8864 & 41 & \\
\hline Graidis C, et al. 2015 & 64 slice MDCT Angiography & Greek, 2572 & $9(0.35 \%)$ & \\
\hline Pan C, et al. 2015 & MSCT Angiography & Chinese, 7469 & 51 & \\
\hline Tongut A, et al. 2016 & MSCT Angiography & Turkish, 2401 & 12 & \\
\hline Rao A, et al. 2017 & 64 slice MDCT Angiography & North Indian, 391 & 3 & \\
\hline Chaosuwannakit N. 2018 & CT Angiography & North-eastern Thailand, 924 & 12 & \\
\hline \begin{tabular}{|l} 
Chaiyagool K, et al. 2018 \\
\end{tabular} & 64 slice MDCT Angiography & Southern Thailand 279 & $3(1.1 \%)$ & \\
\hline Sirasapalli CN, et al. 2018 & 64 slice MDCT Angiography & South Indian, 8021 & 41 & \\
\hline Present study. 2011 & 64-slice CT Angiography & North Indian, 50 & $3(6 \%)$ & \\
\hline
\end{tabular}

In the present study, anomalous origin of RCA was seen only from LPAS, and it was observed in $3(6 \%)$ cases [Table 2 \& 6]. This incidence was quite high. Anomalously originated RCA is a rare congenital cardiac malformation. ${ }^{[24]}$ Houman TM, et al reported that anomalously originated RCA from left sinus of Valsalva is a rare congenital anomaly but frequently causes sudden death in the young. They also suggested that early graft failure had occurred if bypass procedures are used to treat such kind of anomalous origin of RCA. ${ }^{[31]}$ This kind of ectopic RCA is difficult to cannulate because of its slit-like orifice and odd angulation. $^{[3]}$

Several authors found that RCA is the most common anomalous vessel among coronary arteries. ${ }^{[4,23,27,32-34]}$ While some authors found RCA as the second most common anomalous coronary artery. ${ }^{[35-37]}$ Anomalous origin of RCA is often asymptomatic and is found incidentally during evaluation of some cardiac diseases. ${ }^{[38]}$ Although origin of RCA from the left sinus of Valsalva and course between the aorta and pulmonary artery is less frequently associated with symptoms, this condition may be associated with sudden death. ${ }^{[39]}$ In a CT angiographic study, Krupinski $\mathrm{M}$, et al observed that high-risk anatomy features are most common in patients with abnormal RCA origin. These patients also have higher prevalence of chest pain and tend to show higher occurrence of cardiac events in the follow-up than individuals with abnormal LCA origin and abnormal LCx artery origin. ${ }^{[40]}$

Anomalous origin of coronary arteries from aorta is uncommon but significant clinically. Clinical manifestations may vary from asymptomatic patients to those who present with heart failure, syncope and arrhythmias. ${ }^{[41]}$ Anomalous origin of the coronary arteries may be a risk factor for angina pectoris, acute myocardial infarction and sudden death even if there is no atherosclerosis. ${ }^{[23]}$ Roberts WC, et al found fibrosed myocardial patches, small areas of infarcts in patients who suffer sudden death in absence of atherosclerosis. ${ }^{[42]}$ Frescura $\mathrm{C}$, et al observed that in 16 patients out of 27 with isolated anomalous origin of coronary arteries, the final outcome was sudden death. Sudden death occurred in $43 \%$ of right coronary artery origin from left aortic sinus. ${ }^{[43]}$ Clarification of the risk and 
mechanisms of sudden death in patients with coronary anomalies may aid in decisions on intervention. Taylor A J, et al proposed the mechanism of myocardial ischemia and sudden death in these patients and proposed causes include:1) Ostial obstruction due to slit-like coronary orifice. 2) Compression of RCA between aorta and pulmonary artery. 3) Stretching of the RCA with aortic/pulmonary artery distension. Coronary angulation with aortic / pulmonary artery distension. ${ }^{[5]}$ Singhi AK, et al stated that anomalously arising RCA from left coronary sinus can have dynamic narrowing and kinking causing myocardial ischemia and sudden cardiac death. Anomalous artery should be surgically repaired in the symptomatic patients because of risk of ischemia or ventricular arrhythmia and a close follow up is required in asymptomatic patients with exercise restriction as per present guideline. ${ }^{[4]}$ Targeted patients for treatment are those whose anomalous artery is dominant, whose anomalous artery is having proximal intramural course and those who become symptomatic before 35 years of age. ${ }^{[41]}$

Cheatham JP, et al reported origin of RCA from descending thoracic aorta and found atypical and elastotic changes and wall thickening in this RCA. ${ }^{[45]}$ According to Yamanaka O and Hobbs RE, origin of the RCA from pulmonary artery is extremely rare. They found origin of RCA from pulmonary trunk in 2 cases, which is a potentially serious anomaly. ${ }^{[3]}$ Rigatelli $\mathrm{G}$, et al and HakimK, et al reported anomalous origin of RCA from pulmonary artery. ${ }^{[46,47]}$ In a cadaveric study, Vasuki AKM, et al found origin of RCA from pulmonary trunk in three specimens out of fifty. ${ }^{[48]}$ Some authors have reported origin of RCA from LCA. ${ }^{[4,8,9]}$ While some have observed origin of RCA from LAD artery. ${ }^{[7,49-53]}$ Duran C, et al also reported absence of RCA in one case. ${ }^{[51]}$ Chaitman BR, et al; Tanrýverdi H, et al and Aydar Y, et al, reported origin of RCA from LCx artery in one case each. ${ }^{[19,54,55]}$ Harikrishnan $\mathrm{S}$, et al and Chung J, et al found double RCA in one case each. ${ }^{[36,56]}$

If RCA takes origin from above the Sino-tubular (ST) junction, then it is known as high take-off of RCA. In the present study, no case of high take-off of RCA was found whereas several authors reported high take off of RCA. $^{[3,14,24,27,28,43,57-61]}$ Sahni D and Jit I reported an incidence of $3.4 \%$ in males and $1.7 \%$ in females. ${ }^{[57]}$ High takeoff of the coronary arteries usually presents no major clinical problems, but may cause difficulty in cannulating the vessels during coronary arteriography. Selective intubation of the coronary artery may be extremely difficult, especially when the RCA is anomalously located high over the left coronary sinus. ${ }^{[62]}$ Angelini $\mathrm{P}$, et al reported low origination of RCA. ${ }^{[63]}$

Anomalous coronary arteries may be found as an isolated defect or may occur as a part of congenital malformations of the heart. A high incidence of congenital heart diseases was reported by Topaz $\mathrm{O}$, et al in cases of anomalous coronary arteries. Recognition of these anomalous arteries is important in patients undergoing coronary angioplasty or cardiac surgery. ${ }^{[43]}$ In some catheter angiographic studies, the incidence of primary congenital anomalies of coronary arteries is more in males than females. ${ }^{[21,32,35,64]}$ But in a study done by Aydar Y, et al, the incidence found more for females. ${ }^{[5]}$
Cardiac surgeons should take care of anomalous coronary arteries in order to avoid transsection, ligation, or iatrogenic occlusion of anomalous arteries during surgery. ${ }^{[65]}$ Anomalously originated coronary arteries are the second most common cause of athletic-field deaths in the United States. ${ }^{[66]}$ Why an athlete can exercise intensely for several years without symptoms until the sentinel event occurs remains unknown. ${ }^{[6]} \mathrm{Jim} \mathrm{MH}$, et al stated that the RCA anomalously arising from left coronary sinus is associated with early development of Coronary Artery Disease (CAD) while Suryanarayana $P$, et al found that there is no difference in the occurrence of atherosclerosis between anomalous and nonanomalous coronary arteries. ${ }^{[34,67]}$

Coronary artery anomalies should be recognized during life time of a patient by the use of noninvasive procedures to prevent the risk of sudden death and to plan surgical correction if clinically indicated. ${ }^{[43]}$

\section{Conclusion}

In the present study, most common site for origin of RCA was AAS. Anomalous origin of RCA was seen only from LPAS. Anomalous origin of RCA was seen only in male subjects. In all subjects having anomalous origin of RCA from LPAS, RCA coursed between pulmonary trunk and ascending aorta.

\section{References}

1. Standring S, editor-in-chief. Gray's anatomy. The anatomical basis of clinical practice.40thed. Churchill Livingstone: Elsevier;2008.

2. White NK, Edwards JE. Anomalies of the coronary arteries. Report of four cases. Arch Pathol. 1948;45:766-71.

3. Yamanaka O, Hobbs RE. Coronary artery anomalies in 126,595 patients undergoing coronary arteriography. Cath Cardiovasc Diagn. 1990;21:28-40.

4. Topaz O, DeMarchena EJ, Perin E, Sommer LS, Mallon SM, Chahine RA, et al. Anomalous coronary arteries: Angiographic findings in 80 patients. International Journal of Cardiology. 1992;34(2):129-138.

5. Taylor AJ, Rogan KM, Virmani R. Sudden cardiac death associated with isolated congenital coronary artery anomalies. J Am Coll Cardiol. 1992;20:64-67.

6. Molossi S, Mery CM. Controversies Surrounding Coronary Arteries Anomalies in Young Athletes. American College of Cardiology;2015[cited 2019 Feb 7]. Available from: https://www.acc.org latest- incardiology/articles/2015/07/14/08/31/ controversies- surroundingcoronary-arteries- anomalies-in-young-athletes

7. Cansel M, Kurtoğlu E, Yağmur J, Taşolar H, Ermiş N, Açıkgöz N, et al. Abnormal origin of the right coronary artery from the left anterior descending artery. İnönü Üniversitesi Tip Fakültesi Dergisi. 2010;7(3):195-197.

8. Zamani J, Mahmmody Y. Anomalous right coronary artery originating from the left main coronary artery. Iranian Cardiovascular Research Journal. 2009;3(3): 167-169.

9. Chatterjee T, Erne P. Anomalous right coronary artery originating from the mid left main coronary artery. Heart. 2003;89:132.

10. Kragel AH, Roberts WC. Anomalous origin of either the right or left main coronary artery from the aorta with subsequent coursing between aorta and pulmonary trunk: analysis of 32 necropsy cases. Am J Cardiol. 1988;62:771-7.

11. Ho JS, Strickman NE. Anomalous origin of the right coronary artery from the left coronary sinus. Tex Heart Inst J. 2002; 29: 379. 
12. Palimar V, Pamidi N, Rakesh V, Vollala VR, Kumar S, Jetti R. Origin of right coronary artery from the left sinus of Valsalva. International Journal of Anatomical Variations. 2008;1:12-13.

13. Lufukuja GJ. Anomalous origin of the coronary arteries. Italian Journal of Anatomy and Embryology. 2016;121(3):253-257.

14. Kalpana R. A study on principal branches of coronary arteries in humans. Journal of the Anatomical Society of India. 2003;52(2):712.

15. Fazliogullari Z, Karabulut A K, Unver Dogan N, Uysal I I. Coronary artery variations and median artery in Turkish cadaver hearts. Singapore Med J. 2010;51(10):775.

16. Kulkarni JP. Variant anatomy of coronary arteries. Heart India. 2013;1(2):46-51.

17. Reddy MV, Pusala. Anatomical variations in branching pattern and dimensions of coronary arteries: A cadaveric study from south India. IOSR Journal of Dental and Medical Sciences. 2016;15(8): 21-28.

18. Bhele AV, Ughade HM, Shaikh S, Joge US. A study of course, branches and variations of the coronary arteries in the human cadaveric heart. International Journal of Contemporary Medical Research. 2017;4(7):1533-1537.

19. Chaitman BR, Lesperance J, Saltiel J, Bourassa MG. Clinical, angiographic, and hemodynamic findings in patients with anomalous origin of the coronary arteries. Circulation. 1976;53:1:122-31.

20. Söylemez N, Demirbağ R, Hazırolan T, Akpınar O. Anomalous origin of the right coronary artery from the left sinus Valsalva with coronary ectasia. International Journal of Clinical Medicine. 2011;2:269-271.

21. Kimbiris D, Iskandrian AS, Segal BL, Bemin CE. Anomalous aortic origin of coronary arteries. Circulation. 1978;58 (4):606615

22. Wilkins CE, Betancourt B, Mathur VS, Massumi A, De Castro $\mathrm{CM}$, Garcia E, et al. Coronary artery anomalies. A review of more than 10,000 patients from the Clayton cardiovascular laboratories. Journal of Texas Heart Institute. 1988;15:166-173.

23. Kaku B, Shimizu M, Yoshio H, Ino H, Mizuno S, Kanaya H, et al. Clinical features of prognosis of Japanese patients with anomalous origin of the coronary artery. Jpn Circ J. 1996;60(10):731-741.

24. Ayalp R, Mavi A, Serçelik A, Batyraliev T, Gümüsburun E. Frequency in the anomalous origin of the right coronary artery with angiography in a Turkish population. International journal of cardiology. 2002;82(3):253-7.

25. Schmitt R, Froehner S, Brunn J, Wagner M, Brunner H, Cherevatyy $\mathrm{O}$, et al. Congenital anomalies of the coronary arteries: imaging with contrast-enhanced, multidetector computed tomography. European Radiology. 2005;15(6):1110-21.

26. ten Kate GJR, Weustink AC, de Feyter PJ. Coronary artery anomalies detected by MSCT-coronary angiography in the adult. Netherlands Heart Journal. 2008;16(11):369- 375.

27. Namgung J, Kim JA. The prevalence of coronary anomalies in a single center of Korea: Origination, course, and termination anomalies of aberrant coronary arteries detected by ECG-gated cardiac MDCT. BMC Cardiovasc Disord. 2014;14: 48.

28. Chaosuwannakit N. Anatomical variants and coronary anomalies detected by dual-source coronary computed tomography angiography in North-eastern Thailand. Pol J Radiol. 2018;83:e372-e378.

29. Shu-shui W, Ji-mei C, Guo-hong Z, Mei-ping H, Zhi-wei Z, Jian Z. The 'coronary artery sandwich anomaly'. International Journal of Cardiology. 2014;172:e196-e198.

30. Ziegler FV, Pilla M, McMullan L, Panse P, Leber AW, WilkeN, et al. Visualization of anomalous origin and course of coronary arteries in748 consecutive symptomatic patients by 64-slice computed tomography angiography. BMC Cardiovascular Disorders. 2009; 9:54.

31. Houman TM, Sean PB, Philip CC, Robert WS, Charles RM, WilliamCD. Repair of anomalous origin of right coronary artery from the left sinus of Valsalva. Ann Thorac Surg. 2008;85(6):21356.

32. Garg N, Tewari S, Kapoor A, Gupta DK, Sinha N. Primary congenital anomalies of the coronary arteries: A coronary arteriographic study. International Journal of Cardiology. 2000;74(1):39-46.

33. Ouali S, Neffeti E, Sendid K, Eighoul K, Remedi F, Boughzela E. Congenital anomalous aortic origins of the coronary arteries in adults: A Tunisian coronary arteriography study. Archives of cardiovascular disease. 2009;102:201-208.

34. Suryanarayana P, Kollampare S, Riaz IB, Lee J, Husnain M, Luni FK, et al. Presence of anomalous coronary seen on angiogram is not associated with increased risk of significant coronary artery disease. Int J Angiol. 2014;23(4):243-246.

35. Eid AH, Itani Z, Al-Tannir M, Sayegh S, Samaha A. Primary congenital anomalies of the coronary arteries and relation to atherosclerosis: an angiographic study in Lebanon. Journal of Cardiothoracic Surgery. 2009;4:58

36. Harikrishnan S, Jacob SP, Tharakan J, Titus T, Kumar VK, Bhat A, et al. Congenital coronary anomalies of origin and distribution in adults: A coronary arteriographic study. Indian Heart Journal. 2002;54(3):271-275.

37. Lingaraju S, Maurya RK, Sanghvi S. A study of incidence and pattern of coronary artery anomalies in Western Rajasthan, India. International Journal of Research in Medical Sciences. 2016;4(8):3388-3393.

38. Refatllari A, Likaj E, Dumani S, Hasimi E, Goda A. Surgical treatment of anomalous origin of right coronary artery in a patient with mitral stenosis. Open Access Maced J Med Sci. 2016;4(1):131-134.

39. Lauridson JR . Sudden death and anomalous origin of the coronary arteries from the aorta. A case report and review. The American Journal of Forensic Medicine and Pathology. 1988;9(3):236-240.

40. Krupinski M, Urbanczyk ZM, Laskowicz B, Irzyk M, Banys R, Klimeczek $\mathrm{P}$, et al. Anomalous origin of the coronary artery from the wrong coronary sinus evaluated with computed tomography: "high-risk" anatomy and its clinical relevance. Eur Radiol. 2014; 24(10):2353-9.

41. Hamzeh G, Crespo A, Estarán R, Rodríguez MA, Voces R, Aramendi JI. Anomalous origin of right coronary artery from left coronary sinus. Asian Cardiovascular \& Thoracic Annals. 2008; 16:123-126.

42. Roberts WC, Siegel RJ, Zipes DP. Origin of the right coronary artery from the left sinus of Valsalva and its functional consequences: Analysis of 10 necropsy patients. Am J Cardiol. 1982;49:863-8.

43. Frescura C, Basso C, Thiene G, Corrado D, Pennelli T, Angelini A, et al. Anomalous origin of coronary arteries and risk of sudden death: A study based on an autopsy population of congenital heart disease. Journal of Human Pathology. 1998; 29(7): 689- 695.

44. Singhi AK, Bari EA, Banerjee S. Anomalous origin of right coronary artery causing myocardial ischemia in a young patient. Ann Pediatr Card. 2017;10:212-4.

45. Cheatham JP, Ruyle NA, McManus BM and Gammel GE. Origin of the right coronary artery from the descending thoracic aorta: angiographic diagnosis and unique coronary artery anatomy at autopsy. Cathet Cardiovasc Diagn. 1987;13(5):321-4.

46. Rigatelli G, Rigatelli G, Trivellato M. Coronart artery anomaloies: prevalence and clinical profile in elderly patients. Journal of Geriatric cardiology. 2004;1(1):40-43.

47. Hakim K, Boussaada R, Hamdi I, Ouarda F. Anomalous origin of the right coronary artery from the pulmonary artery. Two case reports. The Egyptian Heart Journal. 2014; 66:283-286.

48. Vasuki AKM, Jamuna M, Joy D, Devi MN, Radhika K. Anatomical study of right coronary artery and its variations Cadaveric study. Indian Journal of Clinical Anatomy and Physiology. 2017;4(2):185-189.

49. Simkoff WL, Murphy ES, DeMots H, Khonsari S, Abbruzzese P. Anomalous origin of the right coronary artery from the left anterior descending: angiographic diagnosis in a patient with coronary artery disease. Cathet Cardiovasc Diagn. 1982;8:49-53.

50. Gowda RM, Caccavo ND, Cosme-Thormann BF, Khan IA. Single Coronary Artery: Anomalous Origin of Right Coronary Artery from Left Anterior Descending Artery. Journal of Clinical and Basic Cardiology. 2005;8 (1-4):73.

51. Duran C, Kantarci M, Durur SI, Gulbaran M, Sevimli S, Bayram 
EJ, et al. Remarkable anatomic anomalies of coronary arteries and their clinical importance: A multidetector computed tomography angiographic study. Journal of Computer Assisted Tomography. 2006;30(6):939-48.

52. Balghith M. Anomalous origin of the right coronary artery from the proximal left anterior descending artery and a single coronary artery anomaly: Three case reports. J Saudi Heart Assoc. 2013;25(1):43-46.

53. Pan C, Azhati G, Xing Y, Wang Y, Liu W. Comparison of congenital coronary artery anomalies between Uyghur and Han: A multi slice computed tomography study in Xinjiang, China. Chinese Medical Journal. 2015;128(1):15-19.

54. Tanrýverdi H, Peleci D, Kuru O, Semiz E. Right coronary artery arising as a terminal extension of the left circumflex artery (a rare coronary artery anomaly). Can J Cardiol. 2007;23( 9):737-738.

55. Aydar Y, Yazici HU, Birdane A, Nasifov M, Nadir A, Ulus T, et al. Gender differences in the types and frequency of coronary artery anomalies. Tohoku J. Exp. Med. 2011; 225: 239-247.

56. Chung J, Kim HL, Lim WH, Seo JB, Zo JH, Kim MA, et al. Double right coronary arteries originated from separate ostia with total occlusive lesion in one of the two right coronary arteries. J Lipid Atheroscler. 2017;6(2):97-10.

57. Sahni D, Jit I. Origin and size of the coronary arteries in the northwest Indians. Indian Heart Journal. 1989;41(4):221-8.

58. Kardos A, Babai L, Rudas L, Gaa T, Horvath T, Ta losi L, et al. Epidemiology of congenital coronary artery anomalies: A coronary arteriography study on a central European population. Catheterization and Cardiovascular Diagnosis. 1997;42:270-275.

59. Graidis C, Dimitriadis D, Karasavvidis V, Dimitriadis G, Argyropoulou E, Economou F, et al. Prevalence and characteristics of coronary artery anomalies in an adult population undergoing multidetector-row computed tomography for the evaluation of coronary artery disease. BMC Cardiovascular Disorders. 2015;15:112.

60. Ravi V, Tejesh S. Anatomical variation in branching pattern and dominance in coronary arteries: A cadaveric study. Int J Anat Res, 2017;5(1):3611-17.

61. Tosun V, Korucuk N, Guntekin U. Anomalous high origin of the right coronary artery above the sinotubular junction. EJMO. 2018;2(1):46-48.

62. Douglas JS, Franch RH, King SB. Coronary artery anomalies. In: King SB, Douglas JS, eds. Coronary arteriography and angioplasty. New York: McGraw Hill, 1985; 33-85.

63. Angelini P, Velasco JA, Flamm S. Coronary anomalies incidence, pathophysiology, and clinical relevance. Circulation. 2002;105:2449-2454.

64. Sohrabi B, Habibzadeh A, Abbasov E. The incidence and pattern of coronary artery anomalies in the north-west of Iran: A coronary arteriographic study. Korean Circ J. 2012;42:753-760.

65. Hobbs RE, Millit HD, Raghavan PV, Moodie DS, Sheldon WC. Congenital coronary artery anomalies: clinical and therapeutic implications. Cardiovascular Clinics. 1981; 12(2):43-58.

66. Maron BJ, Thompson PD, Puffer JC, McGrew CA, Strong WB, Douglas PS, et al. Cardiovascular preparticipation screening of competitive athletes. A statement for health professionals from the Sudden Death Committee (clinical cardiology) and Congenital Cardiac Defects Committee (cardiovascular disease in the young), American Heart Association. Circulation. 1996;94:850-6.

67. Jim MH, Siu CW, Ho HH, Miu R, Lee SW. Anomalous origin of the right coronary artery from the left coronary sinus is associated with early development of coronary artery disease. J Invasive Cardiol. 2004;16(9):466-8.

68. Alexander RW, Griffith GC. Anomalies of the coronary arteries and their clinical significance. Circulation. 1956;14:800-805.

69. Hou KY, Jeng CM, Liu YP, Wang TH, Lin TM, Chen SW. Diagnosis of anomalous coronary arteries in64-MDCT. Chin J Radiol. 2007;32:111-119.

70. El-Sharkawy EM. None atherosclerotic coronary anomalies as detected by 64 multidetector computed tomography in patients with typical angina chest pain. Journal of Medical Research Institute. 2007; 28(2):126-30.

71. Srinivasan KG, Gaikwad A, Kannan BRJ, Ritesh K, Ushanandin KP. Congenital coronary artery anomalies: Diagnosis with 64 slice multidetector row computed tomography coronary angiography: A single-centre study. Journal of Medical Imaging and Radiation Oncology. 2008;52(2):148-154.

72. Yildirim D, Oruc F. Coronary artery anatomy,variations-anomalies and incidental extra coronary findings in a multiracial population: A large scale retrospective study with electron beam tomography in Istanbul. Yeditepe Medical Journal. 2009;(10):176-182.

73. Solanki P, Gerula C, Randhawa P, Benz M, Maher J, Haider B. Right coronary artery anatomical variants: Where and how? Journal of invasive cardiology. 2010;22(3):103-106.

74. Shabestari AA, Akhlaghpoor S, Tayebivaljozi R, Fattahi MF. Prevalence of congenital coronary artery anomalies and variants in 2697 consecutive patients using 64-detector row coronary CTangiography. Iran J Radiol. 2012; 9(3):111-21.

75. Abdulghaffar W, Elganayni F, Abou-Issa AH, Almorsy A. Imaging of coronary artery anomalies using ECG-gated 64-row computed tomography angiography. The Egyptian Journal of Radiology and Nuclear Medicine. 2012;43:383-388.

76. Kayan M, Yavuz T, Munduz M, Türker Y, Yeşildağ A, Etli M, et al. Evaluation of coronary artery anomalies using128-slice computed tomography. Türk Göğus Kalp Damar Cerrahisi Dergisi. 2012;20(3):480-487.

77. Tuo G, Marasini M, Brunelli C, Zannini L, Balbi M. Incidence and clinical relevance of primary congenital anomalies of the coronary arteries in children and adults. Cardiology in theYoung. 2013;23:381-386.

78. Opolski MP, Pregowski J, Kruk M, Witkowski A, Kwiecinska S, Lubienska E, et al. Prevalence and characteristics of coronary anomalies originating from the opposite sinus of Valsalva in 8,522 patients referred for coronary computed tomography angiography. Am J Cardiol. 2013;111(9):1361-7.

79. Park JH, Kwon NH, Kim JH, Ko YJ, Ryu SH, Ahn SJ, et al. Prevalence of congenital coronary artery anomalies of Korean men detected by coronary computed tomography. Korean Circulation Journal. 2013;43:7-12.

80. Oliveira CA, Mota P, Basso SP, Catarino RP. Congenital coronary variants and anomalies: Prevalence in cardiovascular multi slice computed tomography studies in a single center. Open Journal of Radiology. 2014;4:163-172.

81. Tongut A, Zyedek ZO, Cerezci I, Erenturk S, Hatemi AC. Prevalence of congenital coronary artery anomalies as shown by multi-slice computed tomography coronary angiography: a singlecentre study from Turkey. Journal of International Medical Research. 2016;44(6):1492-1505.

82. Rao A, Pimpalwar Y, Yadu N, Yadav RK. A study of coronary artery variants and anomalies observed at a tertiary care armed forces hospital using 64-slice MDCT. Indian Heart Journal. 2017;69:81-86.

83. Dhobale MR, Puranik MG, Mudiraj NR. Anatomical study of right coronary artery and its variations in adult human cadavers: developmental basis and clinical significance. International Journal of Anatomy, Radiology and Surgery. 2018;7(4):AO35-AO40.

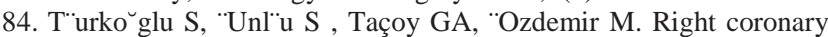
artery originating from the left: Do not miss the diagnosis! Cardiology Research and Practice[Internet]. 2018. Available from https://doi.org/10.1155/2018/1210791

85. Chaiyagool K, Suwannanon R, Hongsakul K. Anatomic variants and anomalies of coronary arteries detected by computed tomography angiography in southern Thailand. Med J Malaysia. 2018;73(3):131-136.

86. Sirasapalli CN, Christopher J, Ravilla V. Prevalence and spectrum of coronary artery anomalies in 8021 patients: A single centre study in South India. Indian Heart Journal. 2018;70:852-856. 
Copyright: ( $)$ the author(s), publisher. Academia Anatomica International is an Official Publication of "Society for Health Care \& Research Development". It is an open-access article distributed under the terms of the Creative Commons Attribution Non-Commercial License, which permits unrestricted non-commercial use, distribution, and reproduction in any medium, provided the original work is properly cited.

How to cite this article: Tomar S, Sharma PK, Manik P, Kumar M. Origin of Right Coronary Artery (RCA): A Multidetector Computed Tomography (MDCT) Coronary Angiographic (CA) Study in North India. Acad. Anat. Int. 2019;5(1):31-39.

DOI: dx.doi.org/10.21276/aanat.2019.5.1.8

Source of Support: Nil, Conflict of Interest: None declared. 